\title{
Antibacterial and Antiviral Effects of Water Catholyte, Oxidal with Methylene Blue and Colloidal Silver
}

\author{
Ignat Ignatov \\ DSc, Professor, Scientific Research Center of Medical Biophysics (SRCMB), \\ N. Kopernik Street, 32, Sofia 1111, Bulgaria
}

\begin{abstract}
Coronavirus COVID-19 is an RNA virus with size $120 \mathrm{~nm}$. It began spreading at the end of 2019 and at the beginning of 2020 in China, and it leads to a severe infectious disease 2019-nCoV. It resembles severe acute respiratory syndrome-related coronavirus (SARSr-CoV), and the new virus is labelled as SARS-CoV-2. Its genome is single-chained with positive strand. It contains a nucleotide with spiral symmetry. The coronavirus SARSr-CoV gets replicated via copying of the genetic material using the enzyme RNA-dependent RNA polymerase.The author considers a complex method of influence over SARS-CoV that includes intake of alkaline water Catholyte with negative oxidation reduction potential (ORP), food supplement Oxidal with Methylene blue and Colloidal Silver.
\end{abstract}

Keywords: SARSr-CoV, water Catholyte, Oxidal with Methylene blue and Colloidal Silver

\section{Introduction}

Phylogenetic and comparative analysis of SARS-CoV E shows that TMD consists of the two nonpolar, neutral amino acids, valine and leucine. They lead to a strong hydrophobicity to the E protein. In SARSr-CoV there is an interaction between $\mathrm{E}$ and $\mathrm{S}$ proteins.The interaction is via disulfide bonds. The C-proteins are positively charged. Viral infections occur mainly by C-terminus of target proteins.

The water Catholyte is obtained during electrolysis in the cathode section of the electrolyzer.

The following reaction is valid for the interaction of Catholyte and the virus:

$2 \mathrm{H}_{2} \mathrm{O}+2 e^{-} \rightarrow \mathrm{H}_{2}+2 \mathrm{OH}^{-}$

In this reaction, is possible the free electrons are released that neutralize the positively charged C-proteins, which are responsible for the viral infections. The doses are high and the achieved effects are significant.

Methylene blue has inhibiting action on viral replication (Oz et al., 2011). Its chemical formula is as follows: $\mathrm{C}_{16} \mathrm{H}_{18} \mathrm{ClN}_{13} \mathrm{~S}$.

There have been a number of successful studies of Methylene blue (MB) with West Nile virus, AIDS -related Kaposi's sarcoma and RNA viruses. There are also positive results with progeria and they show the potential of Methylene blue for interaction with the cell membrane with effects on ATP and mitochondria. Oxidal is not need photoactivation.

The colloidal silver $\mathbf{A g}^{+}$has got inhibiting (diminishing) effect over respiratory enzymes of the micro-organisms by building into the reaction center of the enzymes. Thus it prevents the further alteration of the enzymes (Dondysh, 1964). Colloidal silver makes physical changes in the bacterial membrane, like the membrane damage, which can lead to cellular contents leakage and bacterial death. interact with, and potentially disturb the functioning of biomolecules such as proteins and enzymes. The coronavirus replicase was recently predicted to employ a variety of RNA processing enzymes. The colloidal silver $\mathbf{A g}^{+}$inhibits such copying, and in this way are neutralized the effects of SARSr-CoV-2.

The research from 2005 г. has shown that SARS-CoV has observed in water and is possible to exist 14 days (Wang, X. et al., 2005). (Gundy, P., Gerba, Ch., Pepper, J., 2008). In 2003 there was connection between water and wastewater and SARS-CoV in building in Hong Kong where 300 people (Leung et al. 2003) lived were. For that is important application of water Catholyte with antiviral effects.

\section{Methods and Matherials}

\subsection{Electrolyzer for water Catholyte}

The electrolyzer has two parts, which are separated with semipermiable membrane. The anolyte is obtained at the anode and is acidic fraction. The catholyte is obtained at the cathode and is the alkaline fraction, When the current passes through the water there are redox reactions on the surface of the electrodes. The catholyte is with negative oxidation reduction potential (ORP) in $\mathrm{mV}$. The anolyte is with positive oxidation reduction potential $(\mathrm{ORP})$ in $\mathrm{mV}$. The functional scheme and the reactions are shown in Figure 1. 


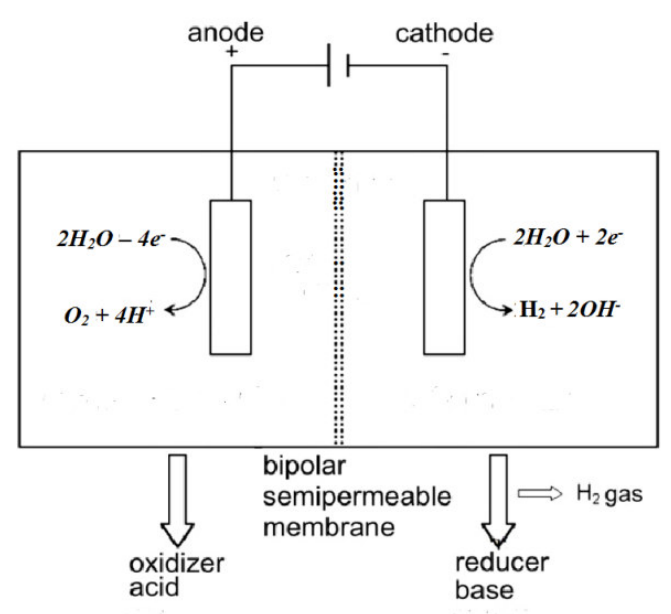

Figure 1. Scheme of the electrolyzer

\subsection{Oxidal}

Oxidal is a sterile aqueous solution that contains:

$-1 \%$ "methylene blue" with chemical formula: $\mathrm{C}_{16} \mathrm{H}_{18} \mathrm{ClN}_{13} \mathrm{~S}$;

$-1 \%$ caffeine;

$-1 \%$ benzoic acid with chemical formula $\mathrm{C}_{6} \mathrm{H}_{5} \mathrm{COOH}$ (as a preservative).

\subsection{Colloidal silver}

In order to obtain colloidal silver with method of electrolysis (Mosin, Ignatov, 2013) the following ingredients are required:

1. Silver electrode with a purity of $99.99 \%$;

2. Tetra- $n$-butylammonium bromide (TBAB)- ammonium salt with bromide;

3. Acetonitrile - coloured liquid solution with chemical formula $\mathrm{CH}_{3} \mathrm{CN}$

The obtaining of colloidal silver can occur via electrolysis (Mosin, Ignatov, 2013). The synthesis method uses tetra- $n$-butylammonium bromide in acetonitrile as a liquid medium for electrolysis. he method of Mosin-Ignatov obtains colloid silver with sizes of $2-7 \mathrm{~nm}$ in a solution of tetra- $n$-butylammonium bromide in acetonitrile. The anode is silver, and the cathode from graphite.

During the process of electrolysis a partial dissolving of the silver anode occurs that leads to saturation of the solution with $\mathbf{A g}^{+}$. At given parameters of the electric current and tension over the electrode, the concentration of $\mathrm{Ag}^{+}$solution is determined by the working time of the electricity source, and the quantity of the aqueous solution.

\section{Results and discussion}

\subsection{Antiviral effects of water Catholyte}

At figure 2 is given the interdependency between the values of $\mathrm{pH}$ and ORP and surviving and micro organisms (Karadzhov et al, 2014). With the red figure is indicated the biosphere of development of micro-organisms. With blue color is indicated the area of suppression of their development. For water Catholyte with strong antiviral effect are needed the following values:

- for $\mathrm{pH}=9.5 \mathrm{ORP} \geq(-650) \mathrm{mV}$;

- for $\mathrm{pH}=10.0 \mathrm{ORP} \geq(-500) \mathrm{mV}$;

- for $\mathrm{pH}=10.5 \mathrm{ORP} \geq(-450) \mathrm{mV}$ 


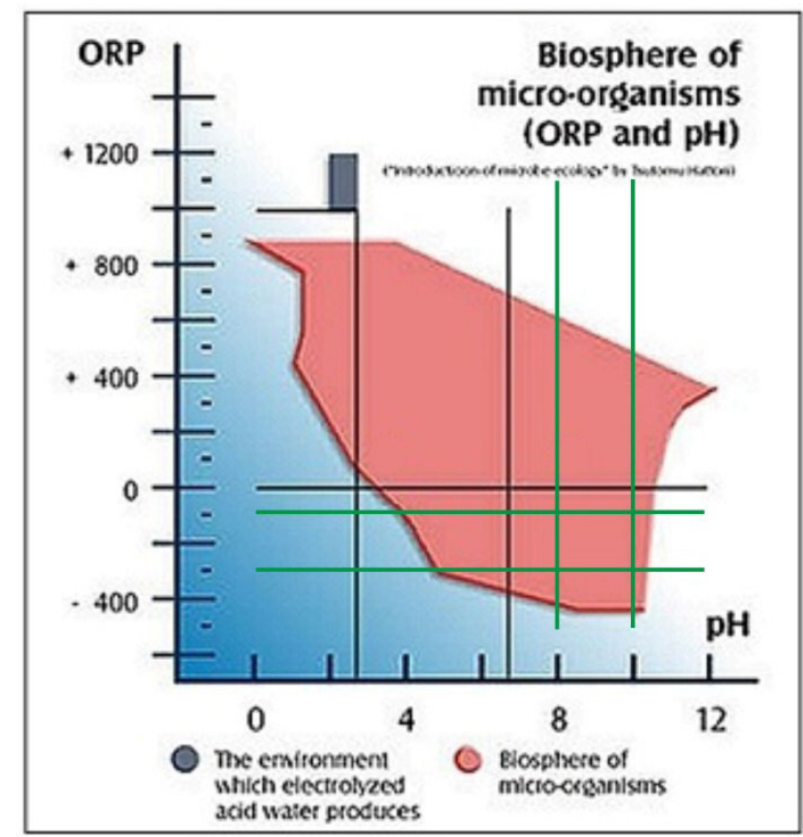

Figure 2. interdependency between the values of $\mathrm{pH}$ and ORP and surviving and micro organisms

The first diagram in figure 3 shows the percentage of viable cells in different types of waters (Miloshev, Guhchev et al. 2015). The bacterial cells of bacteria E. coli DH5a in water are $100 \%$. In catholyte water at the second diagram $15.73 \%$ of the cells survived. In anolyte water $73.60 \%$ of the cells being survived.

Positive results were obtained with water anolyte at the Virus of Classical Swine Fever Virus (Karadzhov, Ivanova et al., 2014) and biocidal effect on on Gram-negative Pathogenic Bacteria.

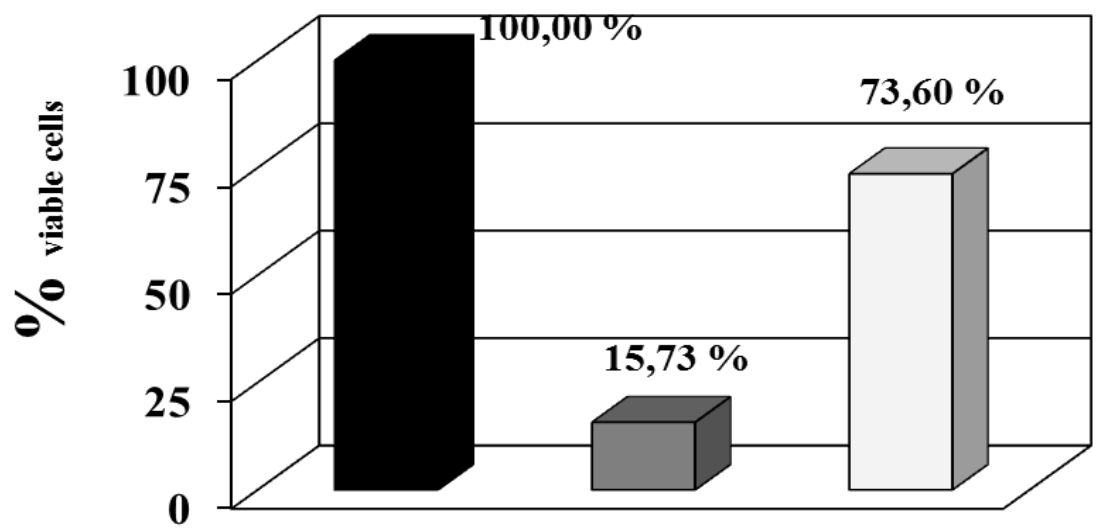

Figure 3. Percentage of viable cells of $E$. coli DH5a after the electrochemical treatment with the catholyte and anolyte relative to the non-electrochemically activated water.

Water Catholyte has structuring of hydrogen bonds among water molecules with anti inflammatory and anti tumor effects (Ignatov, Mosin, 2013).

Water Catholyte stimulates the function of mitochondria and synthesis of ATP (Ignatov et al, 2019; 2020). The presence of nascent hydrogen in Catholyte bestow an antiviral effect upon the water (Vassileva, Mehandjiev et al., 2019). There evidence for beneficial effects on Graffi tumor on hamsters with increasing of blood and immune parameters.

\subsection{Antiviral effects of Oxidal}

When entering mitochondria, methylene blue (MB) acts like an additional electron source. It is firstly reduced to $\mathrm{MBH}_{2}$ by the NADH-dehydrogenase of complex I, and then re-oxidized back to MB by cytochrome c. Cycling between those two forms facilitates electron transportation for ATP synthesis, the major function of the mitochondria. More importantly, it prevents electron leakage for oxidants formation, the toxic side products in mitochondria. $\mathrm{MB}$ also improves mitochondrial function by inducing $\mathrm{PGC} 1 \alpha$, a central mediator of mitochondrial biogenesis, and a few key electron transport chain (ETC) components including cytochrome oxidase (COX II and COX IV . Overall, thise data supports that MB promotes mitochondrial function and 
reduces ROS production.

Currently available results for SARS-CoV, demonstrate that the virus affects the mitochondria in order to suppress the immunity of human body (Nelemans, 2019) (Schoeman, Fielding) Oxidal stimulates the mitochondrial function and ATP. The researched strains of $S$. aureus and E. Coli reveal higher sensitivity to Oxidal in comparison with the control antibiotic Thiamphenicol, but the values are not significantly different (Popova, Petrova, Ignatov, Karadzhov, 2020).

\subsection{Antiviral effect of colloidal silver}

Colloidal Silver in European Union is food additive. The mechanism of action is shown at Fig. 4 (Dondysh, 1964). The coronavirus gets replicated via copying of the genetic material using the enzyme RNA-dependent RNA polymerase. In such a way it prevents the further alteration of the enzyme. The results are "in vitro", on the enzyme in a solution. The colloidal silver is possible $\mathbf{A g}^{+}$inhibits such copying, and in this way the effects of COVID-2019 are neutralized.

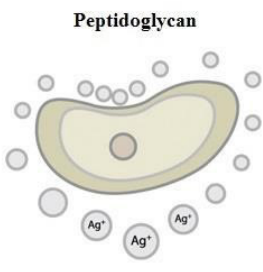

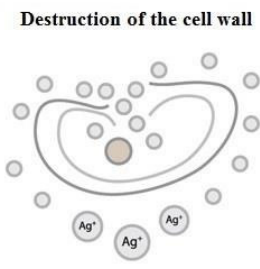

b)

Figure 4. Interaction of $\mathrm{Ag}^{+}$ions of microbial cell: $a$ ) - the membrane protein peptidoglycan and its interaction with $\mathrm{Ag}^{+}$ions; $b$ ) - the process of penetration into the microbial cell of $\mathrm{Ag}^{+}$ions. Dondysh, 1964)

Figure 5 shows the electronic photography of colloidal silver (9) (Darroudi et al., 2011)

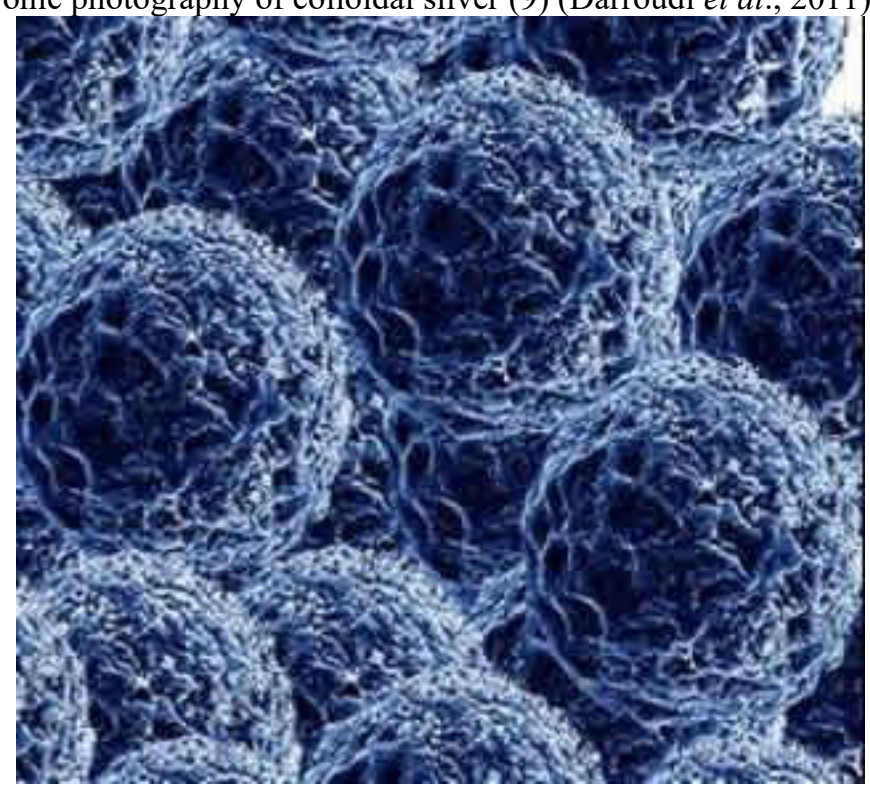

Figure 5. Electron micrographs of colloidal silver with a size of $5 \mathrm{~nm}$ (Darroudi et al., 2011)

\subsection{Antiviral Doses of water Catholyte, Oxidal and Colloidal Silver}

When water Catholyte is used, it is recommended to drink it 1 hour before or after a meal. It is necessary for $\mathrm{pH}$ to be over 9.5 and ORP in the range of $(-700-400) \mathrm{mV}$, otherwise the increase of $\mathrm{pH}$ might decrease ORP and thus negate the effects of Catholyte.

Oxidal can be applied in rather high doses, but research with people show the optimal doses of "methylene blue" per person per day to be around $15 \mathrm{mg}-16 \mathrm{mg}$. When colloidal silver is used, the doses need to be precisely defined.

Daily dosage: $5 \mu \mathrm{g}$ micro g per $1 \mathrm{~kg}$ body weight, ex.5 $\mu \mathrm{g} \mathrm{x70} \mathrm{kg} \mathrm{body} \mathrm{weight}=350 \mu \mathrm{g}=0.00035 \mathrm{~g}$.

\section{Conclusions and discussion}

For COVID-19 the influence is with antibodies against viral proteins binding to cell receptors (via blood, intravenously). There are applyed the folloing drugs again coronavirus $S A R S-C o V-2$-Remdesivir and Kaletra. 
The potential anti-HCoV repurposable drugs are - melatonin, mercaptopurine, and sirolimus.

The author suggests the use of three products - water Catholyte, Oxidal and Colloidal Silver for prevention and as an additional method of therapy for infectious disease 2019-nCoV caused by the virus (SARSr-CoV). The effects target the cell membrane, ATP and mitochondria.

The precise dosage leads to the following effects:

1. The negative electrons reduce the positive charge of $\mathrm{C}$-protein, and thus reducing the number of penetrated viruses inside the cell.

2. The virus SARS-CoV affects the mitochondria in order to suppress the human immunity. Oxidal stimulates the function of mitochondria and ATP.

3. The colloidal silver $\mathbf{A g}^{+}$possesses inhibiting effects over the respiratory enzymes of micro-organisms. $\mathbf{A g}^{+}$ incorporates into the reaction center of the enzyme. In such a way it prevents the further alteration of the enzyme. It is "in vitro", on the enzyme in a solution.

4. As an additional antiviral remedy, we also recommended intake of high doses of Vitamin C.

One of the researchers Wolfgang Luepke suggests hyper immunization of calves with SARS-CoV-2. In doing so antibodies serum can be obtained for therapeutic intervention in people. It can be in the form of breathing aerosol, thus accomplishing passive immunity. In the cells, antibodies are formed, and from passive the immunity becomes active.

\section{References}

Atamna, H.\&Kumar, R. (2010) Protective Role of Methylene blue in Alzheimer's disease via Mitochondria and Cytochrome c Oxidase, J Alzheimers Dis.20 (Suppl 2), S439-452.

Bahir, V.M., Liakumovich, A.G., Kirpichnikov, P.A., Spector, L.E.\&Mamajanov, U.D. (198)The Physical Nature of the Phenomenon of Activation Substances. Izv. UzSSR. Ser. Tehn. Sciences, 1: 60-64.

Darroudi, M., Ahmad, M.B.\&Zamiri, R. (2011) Time-dependent Effect in Green Synthesis of Silver Nanoparticles. International Journal of Nanomedicine, 6: 677-681.

Dondysh, L.M. (1964) Inhibitory Effect of Silver on Some Enzymatic Systems. Questions and Exogenous Organic Neuropsychiatric Disorders/ in Materials of Scientific Conf., State Institute of Psychiatry USSR, Ministry of Health. - Moscow: State. Institute of Psychiatry USSR Ministry of Health, 2: 143-165.

Floyd R.A.; Schneider J.E.\&Dittmer D.P. (2004) Methylene blue Photoinactivation of RNA Viruses, Antiviral Research, 61 (3): 141-51.

Gluhchev, G., Ignatov, I., Karadzhov, S., Miloshev, G., Ivanov, N.\&Mosin, O. V. (2015) Studying of Virucidal and Biocidal Effects of Electrochemically Activated Anolyte and Catholyte Types of Water on Classical Swine Fever Virus (CSF) and Bacterium E. coli DH5, Journal of Medicine, Physiology and Biophysics.13: $1-17$.

Gundy, P., Gerba, Ch., Pepper, J. (2008) Survival of Coronaviruses in Water and Wastewater, Food and Environmental Virology, 1 (10).

Ignatov, I.\&Mosin, O.V. (2013) Methods for the Preparation of Colloidal Silver Nanoparticles and Spheres of Their Practical Application Field, Bulletin of Science and Education,3: 30-42.

Ignatov, I., Gluhchev, G., Karadzhov, G., Yaneva, I., Valcheva, N., Dinkov, G,, Popova, T., Petrova, T., Mehandjiev, D.\&Akszjonovich, I. (2020) Dynamic Nano Clusters of Water on Waters Catholyte and Anolyte: Electrolysis with Nano Membranes, Physical Science International Journal, 24 (1): 46-54.

Ignatov, I., Karadzhov, S., Atanasov, A., Ivanova, E.\&Mosin, O. V. (2014) Electrochemical Aqueous Sodium Chloride Solution (Anolyte and Catholyte) as Types of Water. Mathematical Models. Study of Effects of Anolyte on the Virus of Classical Swine Fever Virus, Journal of Health, Medicine and Nursing, 8: 1-28.

Ignatov, I., Mosin, O. V. (2013) Structural Mathematical Models Describing Water Clusters, Journal of Mathematical Theory and Modeling,3 (11): 72-87.

Ignatov, I. (2019) Electrochemically Activated Water Catholyte for Activation of Shape and Recovery in the Sport, Int. Conference on Medicine and Football, Sofia, Bulgaria, Journal of Medicine and Sport; 3-4.

Ignatov, I., Gencheva, N., Marinov, T., Yaneva, I., Angelcheva, M., Dinkov, G.\& Angushev, I. (2020) Electrochemically Activated Water Catholyte for the Activation of Hydrogen Ions and ATP for Sport's Shape and Recovery, International Journal of Medical and Pharmaceutical Case Reports.

Ignatov, I., Toshkova, R.,Gluhchev, G.\&Zvetkova, E. (2019) Results with IR Spectroscopy of CortiNon+ on the Development of Experimental Graffi Tumor on Hamsters, European Reviews of Chemical Research, 6 (2): 61-67.

Karadzhov, S., Atanasov, A., Ivanova, E., Mosin, O. V.\&Ignatov, I. (2014) Mathematical Models of Electrochemical Aqueous Sodium Chloride Solutions (Anolyte and Catolyte) as Types of Water. Study of the Effects of Anolyte on the Virus of Classical Swine Fever Virus, Journal of Health, Medicine and Nursing, 5: 30-55.

Kim, S.; Kim, D.\&Lee, B. (2020) Insufficient Sensitivity of RNA Dependent RNA Polymerase Gene of SARS- 
CoV-2 Viral Genome as Confirmatory Test using Korean COVID-19 Cases. Preprints.

Lai, J., Luo, S.\&Ho, L. (2018) Signaling Pathways of SARS-CoV In Vitro and In Vivo, Analysis of Proteins that Interact with Nucleocapsid Protein of SARS-CoV using 15-mer Phage-displayed Library, Biochem. Pharmacol, 156:348-356.

Lai, Chih-Cheng et al. (2020) Severe Acute Espiratory Syndrome Coronavirus 2 (SARS-CoV-2) and Coronavirus Disease-2019 (COVID-19): The Epidemic and the Challenges, International Journal of Antimicrobial Agents, 55 (3): 105924.

Leung, W. K., To, K. F., Chan, P. K. S., Chan, H. L. Y., Wu, A. K. L., Lee, N., et al. (2003). Enteric Involvement of Severe Acute Respiratory Syndrome-associated Coronavirus Infection. Gastroenterology, 125, 1011-1017.

Mosin, O. V.\&Ignatov, I. (2013) Preparation of Nanoparticles of Colloid Silver and Spheres of Their Practical Using, Nanoengeneering, 5:23-30.

Mosin, O.V.\&Ignatov, I. (2014) Methods for the Preparation of Colloidal Silver Nanoparticles, Nano and Microsystems, 2: 46-52. 34.

Nelemans, T.\&Kikkert M. (2019) Viral, Innate Immune Evasion and the Pathogenesis of Emerging RNA Virus Infections, Viruses, 11 (10), 961.

Oz, M. et al. (2011) Cellular and Molecular Actions of Methylene Blue in the Nervous System, Medicinal Research Reviews; 31 (1): 93-117.

Papin J.F.; Floyd R.A.\&Dittmer D.P. (2005) Methylene Blue Photoinactivation Abolishes West Nile Virus Infectivity in Vivo. Antiviral Research; 68 (2): 84-7.

Popova, T., Petrova, T.\&Karadzhov, S. (2016) Investigation of the Biocidal Effect of Electrochemically Activated Aqueous Sodium Chloride Solution on Gram-negative Pathogenic Bacteria, Int. J. Curr. Microbiol. App. Sci.5 (1): 624-632.

Popova, T., Petrova, T., Ignatov, I.\&Karadzhov, S. (2020) Preliminary in vitro Investigations on the Inhibitory Activity of the Original Dietary Supplement Oxidal ${ }^{\circledR}$ on Pathogenic Bacterial Strains, Journal of Advances in Agriculture.

Qing, Y. et al. (2018) Potential Antibacterial Mechanism of Silver Nanoparticles and the Optimization of Orthopedic Implants by Advanced Modification Technologies, Int J Nanomedicine. 13: 3311-3327.

Tardivo, J.P.; Del Giglio, A.; Paschoal, L.H.\&Baptista, M.S. (2006) New Photodynamic Therapy Protocol to Treat AIDS-related Kaposi's Sarcoma, Photomedical Laser Surgery, 24 (4): 528-31.

Reidy, B. et al. (2013) Mechanisms of Silver Nanoparticle Release, Transformation and Toxicity: A Critical Review of Current Knowledge and Recommendations for Future Studies and Applications, Materials, 6, 2295-2350.

Schoeman, D, Fielding, B., Coronavirus Envelope Protein: Current Knowledge, 2019, Virology Journal, 69.

Tardivo, J. (2005) Methylene Blue in Photodynamic Therapy: From Basic Mechanisms to Clinical Applications, Photodiagnosis and Photodynamic Therapy, 2 (3): 175-191.

Toshkova, R., Zvetkova, E., Ignatov, I.\& Gluhchev, G. (2019) Effects of Catholyte Water on the Development of Experimental Graffi Tumor on Hamsters, Bulgarian Journal of Public Health, 2019 11, (3): 60-73.

Toshkova, R., Ignatov, I., Zvetkova, E.\&Gluhchev, G. (2019) Effects of Catholyte Water on the Development of Experimental Graffi Tumor on Hamsters, European Journal of Medicine, 7(1): 45-56.

Vassileva, P., Voykova, D., Ignatov, I., Karadzhov, S., Gluhchev, S., Ivanov, N.\&Mehandjiev, D. (2019) Results from the Research of Water Catholyte with Nascent (Atomic) Hydrogen, Journal of Medicine, Physiology and Biophysics, 52: 7-11.

Weiss, S.\&Navas-Martin, S. (2005) Coronavirus Pathogenesis and the Emerging Pathogen Severe Acute Respiratory Syndrome Coronavirus, Microbiol Mol Biol Rev. 69 (4): 635-664.

Wang, X. (2005) Study on the Resistance of Severe Acute Respiratory Syndrome-Associated Coronavirus, J Virol Methods, 126 (1-2):171-7.

Warren TK, Jordan R, Lo MK, Ray AS, Mackman RL, Soloveva V, et al.. (2016) Therapeutic Efficacy of the Small Molecule GS-5734 against Ebola virus in Rhesus Monkeys; Nature. 531

Xiong, Z. M. et al. (2016) Methylene Blue Alleviates Nuclear and Mitochondrial Abnormalities in Progeria, Aging Cell, 15: 279-290.

Xiang, D. et al. (2011) Inhibitory Effects of Silver Nanoparticles on H1N1 Influenza A virus in vitro, Journal of Virological Methods, 178 (1-2): 137-142.

Zhou, Y. et al. (2020) Network-based Drug Repurposing for Novel Coronavirus 2019-nCoV/SARS-CoV-2, Cell Discovery: 6.

Ziebuhr J. (2005) The Coronavirus Replicase, Curr Top Microbiol Immunol; 287:57-94. 